\title{
Orthodontically Management of Non-extraction Class-II Division 2 Malocclusion- A Case Report
}

\author{
Jahan $\mathrm{H}^{1}$ BDS, FCPS, Chawdhury HSR ${ }^{2}$ BDS, Haq ME ${ }^{3}$ BDS, D. Orth, RCS, FCPS (Hon.) \\ and Hossain $\mathrm{MZ}^{3}$ BDS ,PhD,
}

\begin{abstract}
A patient of 21 years old presented with Class II division 2 malocclusion and deep overbite, was treated by fixed orthodontic therapy. After completion of the treatment, extreme deep bite was corrected, proclination of upper anterior teeth and patient was satisfied with new position of his upper anterior teeth.
\end{abstract}

Key Words: Class II division 2 malocclusion, deep overbite, deep curve of spee. (Bangladesh Journal of Orthodontics and Dentofacial Orthopedics, Vol. 2, No. 2, April 2012, p 46-47).

\section{INTRODUCTION}

Class II division 2 is a distinct category of malocclusion having a high incidence of familial inheritance. ${ }^{1}$ It is characterized by the permanent mandibular incisors occluding posterior to the cingulum plateau of retroclined permanent maxillary incisors. This gives rise to a reduced overjet $\&$ frequently in increased overbite. Clinically, the permanent maxillary central incisors are retroclined and the maxillary lateral incisors are proclined and mesiolabially rotated.However, all four permanent maxillary incisors may be retroclined with or without facially displaced \& proclined permanent maxillary canines. The relationship of the labial soft tissues to the permanent maxillary incisors has been implicated as the principal etiological factor in the development relapse of Class II division-2 malocclusion. ${ }^{2-7}$ Specially, the maxillary incisors retroclined is thought to result from increased resting lips pressure as a consequence of a combination hyperactivity of the labial musculature and higher resting lip line. . $, 7,8^{-1}$

\section{CASE REPORTS AND DIAGNOSIS}

The patient Md. Golam Mostafa, 21 years old adult male reported with the chief compliant of backwardly placed upper four front teeth and completely covered the lower front teeth. He had a slight convex facial profile with decreased lower anterior facial height, high lip line and hyperactive lower lip with deep labiomental depression, and prominent chin on extra-oral examination. Intra-oral examination showed healthy soft tissues with acceptable oral hygiene. Dentition showed the presence of all permanent teeth except lower right third molar. Angel's Class II division 2 dental relationship with Class II molar relationship on right side and Class I on left side with deep traumatic bite of 12 $\mathrm{mm}$ and $01 \mathrm{~mm}$ overjet and deep curve of spee.

\section{CEPHALOMETRIC ANALYSIS}

It revealed Class II division 2 dental relation on Class I skeletal base. Small gonial angle with horizontal type of face and interincisal angle is obtuse.

\section{ORTHOPANTOMOGRAM}

It revealed presence of all permanent teeth except lower left third molar and lower right molar (impacted).

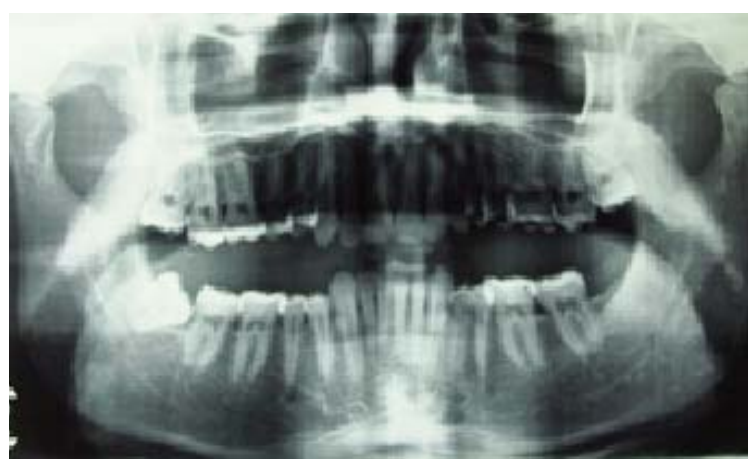

Figure $2:$ Pre treatment orthopantomogram

\section{TREATMENT OBJECTIVES}

Standard edgewise fixed appliance system was used to treat this case despite of a lot of limitation to achieve the desired treatment goals \& try to satisfy the patient's demand.

Treatment objectives are based on model analysis and clinical features.

1. Correction of traumatic bite.

2. Flaring of the maxillary anterior segment with multilooped arch wire.

3. Correction of the curve of spee.

4. Correction of interincisal angle.

5. Establishment of functional occlusion.

6. Improvement of dental and facial aesthetics.

7. Restoration of proper masticatory efficiency.

${ }^{1}$ Dr. Hasnat Jahan, Lecturer, Dept. of Orthodontics, Dhaka Dental College and Hospital, ${ }^{2}$ Dr.Himadri Shekhar Roy Chowdhury, FCPS Trainee, Dept. of Orthodontics, Dhaka Dental College and Hospital, ${ }^{3}$ Professor Dr. Mohammad Emadul Haq, Supernumarary Professor and Head, Dept. of Orthodontics, City Dental College and Hospital and ${ }^{4}$ Professor Dr. Md. Zakir Hossain, Professor and Head, Dept. of Orthodontics, Dhaka Dental College and Hospital, 


\section{TREATMENT PLAN AND PROGRESSION WITH} MECHANICS

Therefore, treatment was planned as follows -

1. Flaring of the maxillary anterior segment with multilooped arch wire (0.014" s.s wire).

2. Bite opening by using wire $\left(0.016^{\prime \prime}\right.$ s.s wire) with reverse curve of spee.

3. Spacing created by flaring of maxillary anterior segment was closed by contraction loop arch wire $\left(0.017^{\prime \prime} x 0.025^{\prime \prime}\right.$ rectangular arch wire).

4. Arch coordination and interdigitation of both arches was done by using vertical elastic.

5. Retention by Hawley retainer.

6. Follow up.
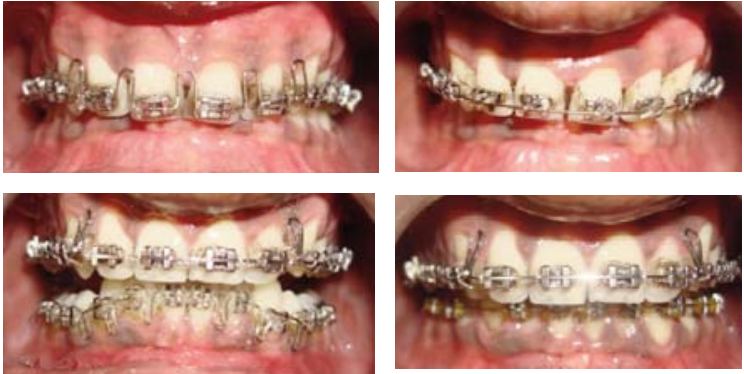

Intraoral photograph (during treatment)

Pictures of Pre-treatment \& Post-treatment
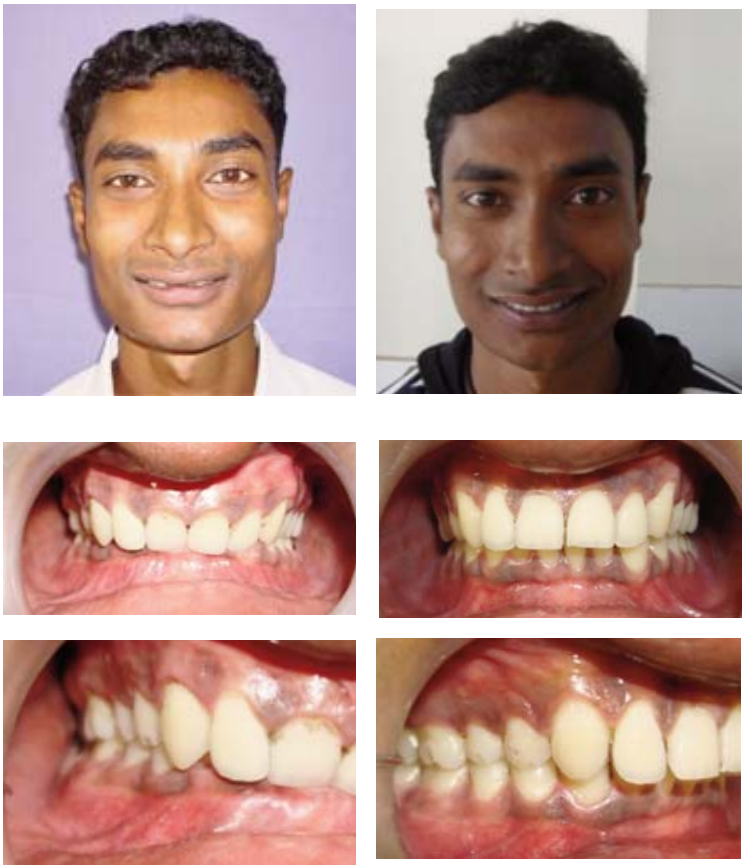

Pre-treatment

Post-treatment
Pre-treatment

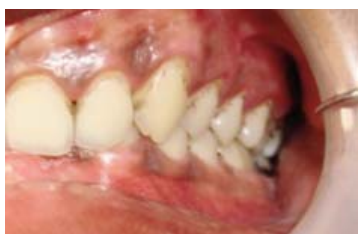

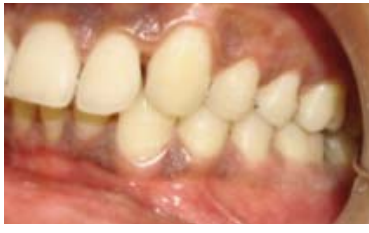

Post-treatment

\section{RESULTS}

Improvement of functional occlusion and aesthetic relationship were achieved by correction of interincisal angle. The relationship of both dentitions were improved. The lower anterior facial height was slightly increased and correction of traumatic bite with proclination of upper anterior segment was achieved which satisfied the patient.

\section{DISCUSSION \& CONCLUSION}

Finally, use of standard edge-wise fixed appliance with maximum anchorage control helped the patient to improve their functional, dental and aesthetic relationship. Reduction of interincisal angle and establishment of guidance between the maxillary and mandibular incisors is important for the stability to be achieved in overbite correction. Correction of traumatic bite and proclination of upper anterior segment achieved is satisfactory with certain limitations. Correction was retained by insertion of the Hawley retainer to the patient.

\section{REFERENCES:}

1. Ridley DR. some factors concerned with the reduction of excessive overbite in Angle's class-II division-2 malocclusion. Trans $\mathrm{Br}$ Soc Study.Orthod.1960;118-140.

2. Nicol WA. The lower lip and upper incisor teeth in Angle's class-II division-2 malocclusion. Dent.Pract.1963;14:179-182.

3. Posen AL.The influence of maximum perioral and tongue force on the incisor teeth. Angle Orthod.1972; 42:245-309.

4. Mills JRE. The problem of overbite in class-II, division 2 malocclusion. BrJ Orthod. 1973; 1: 34-48.

5. Fletcher GGT. The retroclined upper incisor. Br J Orthod. 1975; 2 207-216.

6. Luffingham JK. The lower lip and the maxillary central incisors. Eur J Orthod. 1982;4:263-268.-130.

7. Karisen AT. Craniofacial characteristics in children with Angle Class II div. 2 malocclusion compared with extreme deep bite.Angle Orthod. 1994; 64: 123-130.

Corresponds to:

Dr. Hasnat Jahan BDS, FCPS

Lecturer

Dept. of Orthodontics

Dhaka Dental College and Hospital

Cell : +8801819649817,E-mail : drhasnatjahan@gmail.com 